\title{
Endoscopic Resection of a Cerebellopontine Angle Meningioma via a Retrosigmoid Approach
}

\author{
Frederick Luke Hitti ${ }^{1}$ John Y.K. Lee ${ }^{1}$ \\ ${ }^{1}$ Department of Neurosurgery, Pennsylvania Hospital, Philadelphia,
Pennsylvania, United States
}

J Neurol Surg B 2019;80(suppl S3):S310.
Address for correspondence Frederick Luke Hitti, MD, Department of Neurosurgery, Pennsylvania Hospital, 800 Spruce Street, Philadelphia, PA 19107-6192, United States, (e-mail: frederick.hitti@uphs.upenn.edu).

\begin{abstract}
Keywords

- meningioma

- endoscopic

- retrosigmoid

- cerebellopontine angle
\end{abstract}

A variety of lesions may arise within the cerebellopontine angle (CPA). Schwannomas and meningiomas are most commonly found in this location. Imaging characteristics of meningiomas include hyperdensity on head computed tomography (CT) and avid contrast enhancement on T1-weighted postcontrast magnetic resonance imaging (MRI). Here, we present the case of a 49-year-old woman with enlarging right CPA meningioma. The patient reported mild hearing loss on the right but her neurological exam was otherwise benign. Since the lesion was enlarging and symptomatic, the patient was offered resection of the mass for diagnosis and treatment via an endoscopic retrosigmoid approach. We provide a video that illustrates the steps taken to resect this mass endoscopically. After cerebrospinal fluid (CSF) was drained to achieve brain relaxation, the tumor was visualized. The tumor had a rich vascular supply and had the appearance of a typical meningioma. The bipolar was used to cauterize the tumor's vascular supply. The tumor capsule was then opened with the microscissors. The round knife, suction, and ultrasonic tissue debrider were used to debulk the tumor. After internal debulking of the tumor, the capsule was dissected off the cerebellum and mobilized. A combination of blunt and sharp dissection was done to free the tumor capsule from the adjacent structures. Inferiorly, the lower cranial nerves were visualized. Tissue pathology confirmed a diagnosis of grade I meningioma. A gross total resection was achieved and the patient remained neurologically stable, postoperatively. Furthermore, T1-weighted postcontrast brain MRI, 1 year after surgery, showed no residual.

The link to the video can be found at: https://youtu.be/X9c_inLp-So. received

May 1, 2018 accepted after revision November 11, 2018 published online February 26, 2019
DOI https://doi.org/

10.1055/s-0039-1677855. ISSN 2193-6331. (c) 2019 Georg Thieme Verlag KG Stuttgart · New York
License terms

c) $(1) \$$ 